“C 2017 IEEE. Personal use of this material is permitted. Permission from IEEE must be obtained for all other uses, in any current or future media, including reprinting/republishing this material for advertising or promotional purposes, creating new collective works, for resale or redistribution to servers or lists, or reuse of any copyrighted component of this work in other works." 


\title{
Direct Torque Control with a Modified Switching Table for a Direct Matrix Converter based AC Motor Drive System
}

\author{
Jianwei Zhang ${ }^{1}, \mathrm{Li} \mathrm{Li}^{1}$, David Dorrell ${ }^{2}$, and Youguang Guo ${ }^{1}$ \\ ${ }^{1}$ Faculty of Engineering and IT, University of Technology Sydney, Sydney, Australia \\ ${ }^{2}$ University of KwaZulu-Natal, Howard College Campus, Durban, South Africa \\ Email: Jianwei.Zhang@uts.edu.au,Li.Li@uts.edu.au,dorrelld@ukzn.ac.za and Youguang.Guo-1@uts.edu.au
}

\begin{abstract}
The direct matrix converter has been regarded as a promising $\mathrm{AC} / \mathrm{AC}$ conversion topology and it is being researched. Motor drives are one of the main potential applications of the matrix converter. This paper carries forward the application of matrix converters in $\mathrm{AC}$ motor drives using direct torque control (DTC). In the common DTC scheme for the matrix converter, two vectors with the maximum amplitudes are used to control the torque and flux. In the proposed approach, the input voltage vector sectors are redefined, therefore a modified and simplified switching look-up table is obtained. In this case the most appropriate vector to be applied is uniquely determined and the number of switch actions are reduced. The excellent dynamic performance is obtained by selecting the maximum vector. Flux and speed are controlled effectively. Simulation work is carried out for an induction motor and results verify the effectiveness of the proposed DTC control in matrix converter based AC drive systems.
\end{abstract}

Index Terms-Matrix Converter, Direct Torque Control (DTC), Motor Drive System

\section{INTRODUCTION}

Direct torque control (DTC) was first presented in [1] for the high performance control of an induction motor. As its name implies, DTC controls the torque and flux directly. It is a simple yet powerful control technique for motor drives and it offers various benefits including fast torque response, robustness, no coordinate transformations (angle detection), no modulation stage, and no current controllers are required [2], [3]. DTC does not require any other motor parameters except for the stator resistance; this enhances the robustness of the controller. DTC can also operate in sensorless mode torque control mode. These contribute to the fast development of DTC, in both research and industry, for the applications of high performance drives [4].

However, there are some drawbacks associated with the DTC. One of the main issues is the high torque and flux ripples [5] in addition to the variable switching frequency. The voltage source inverter (VSI) is most widely adopted converter in motor drive applications. In conventional DTC for a VSI based drive system, the flux locus is split into six sections while only eight vectors are available in the VSI to generate the required vector. Therefore, the exact required vector is hard to produce perfectly, which results in the flux and torque ripples. A lot of research efforts have been dedicated to dealing with this problem [6], [7]. These include applications of new converters such as multilevel inverters [8], [9] and matrix converters [10], [11] because they can produce more vectors for DTC control.

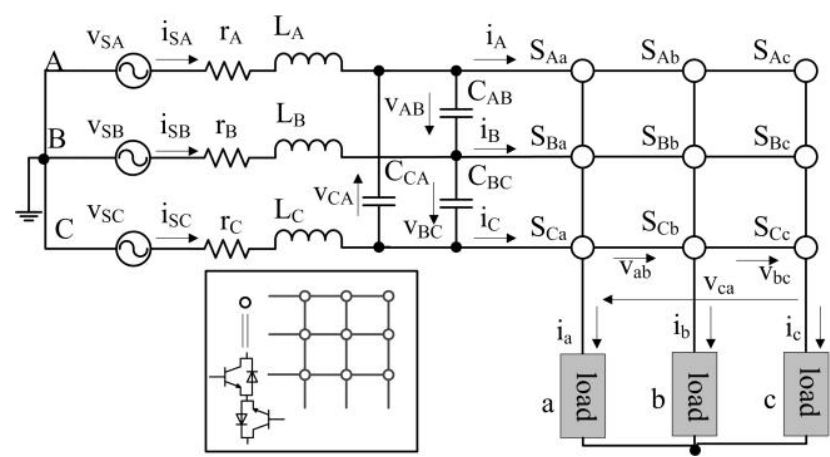

Fig. 1. A three-phase direct matrix converter system with input filters.

Compared with the VSI, matrix converters do not require bulky energy storage elements and they have been researched because of this feature. A $3 \times 3$ direct matrix converter (MC), as shown in Fig. 1, is a flexible power converter which is capable of bidirectional power flow, sinusoidal waveform, regeneration, controllable input power factor and compact volume [12]. Matrix converters are especially suitable for the applications where volume and lifetime are crucial factors, such as military [13] and aerospace [14] applications. They can also be applied in fields where the traditional back-to-back converter usually plays a predominant role such as the interface of two AC systems, FACTS [15], [16], renewable energy systems [17], and electric vehicle motor drives [18].

Thanks to the bidirectional power flow capability, a matrix converter based drive system, as shown in Fig. 2, does not require the braking chopper which is essential in the VSI based driver to absorb the energy during motor deceleration or reverse rotation if a back-to-back inverter system is not used. Therefore, the efficiency is improved and maintenance is alleviated. Recently matrix converter based motor drives have gained much popularity particularly in academia [13]. Combining the advantages of DTC and the matrix converter, DTC controlled matrix converter drivers were initially proposed in [2]. In this work, three hysteresis controllers were employed to control the electromagnetic torque, stator flux and input power factor simultaneously by selecting the most opportune voltage vector available in the matrix converter. Since matrix converters generate more voltage vectors that are suitable for DTC control, the control flexibility is enhanced. Most of the work utilizes this flexibility to control the matrix converter input power factor [2], [5]. This extra control objective introduces an extra hysteresis comparator contributing to heavier 


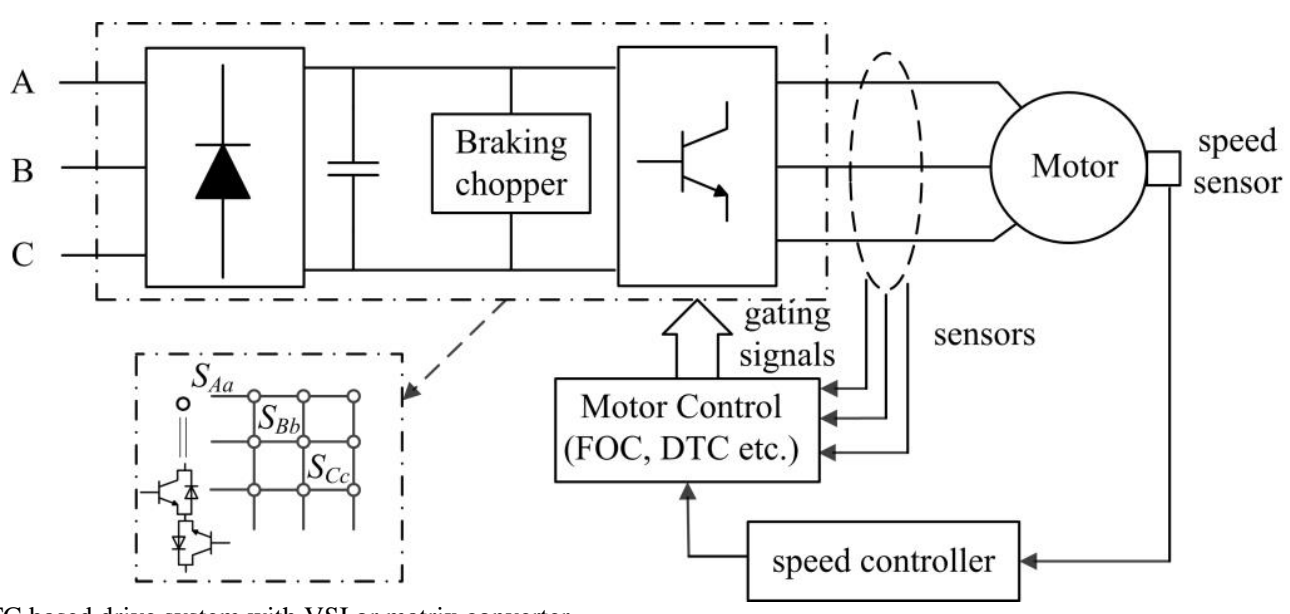

Fig. 2. The DTC based drive system with VSI or matrix converter.

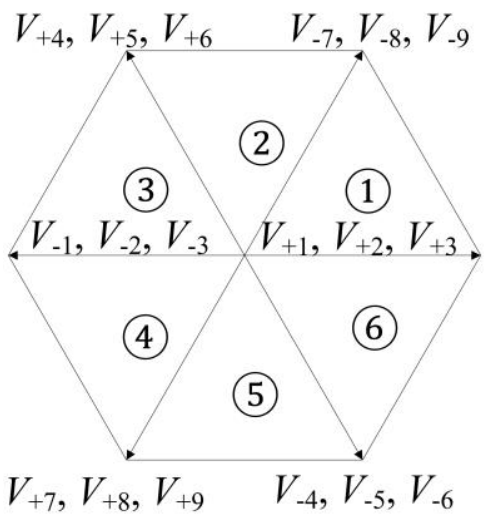

(a)

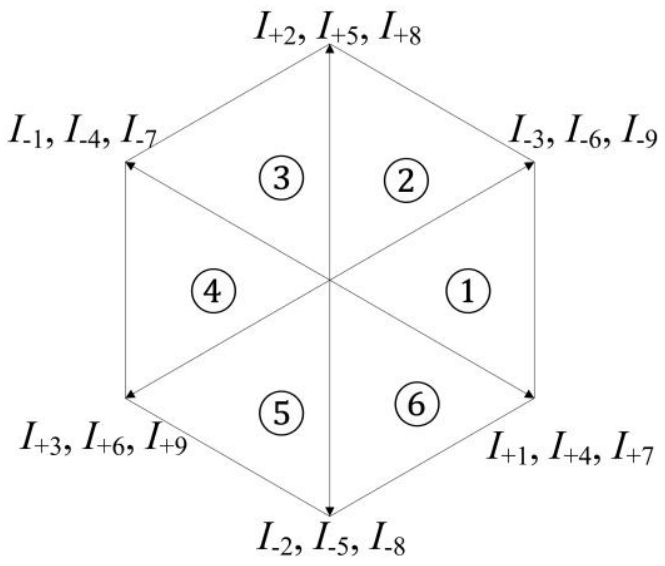

(b)

Fig. 3. Matrix converter (a) input voltage and (b) output current vectors hexagon.

computation burden, more switching actions, and switching losses.

This paper modifies and simplifies the traditional DTC switching table for the matrix converter based driver such that the selected voltage vector for each stator flux sector is uniquely determined. The transition is smoother between switching actions, thus switching losses are reduced. The speed control mode is based on a PI controller and it is tested in this paper.

The matrix converter space vectors are described in Section II and the induction motor model is described in Section III. Section IV presents the DTC control for the matrix converter drivers followed by the simulation results in Section V. Section VI concludes the paper.

\section{MATRIX CONVERTER AND SPACE VECTORS}

As shown in Fig. 1, a three-phase direct matrix converter consists of nine bidirectional switches. These switches form a $3 \times 3$ switch matrix so that

$$
\begin{aligned}
& {\left[\begin{array}{c}
V_{a} \\
V_{b} \\
V_{c}
\end{array}\right]=\left[\begin{array}{lll}
S_{A a} & S_{B a} & S_{C a} \\
S_{A b} & S_{B b} & S_{C b} \\
S_{A c} & S_{B c} & S_{C c}
\end{array}\right]\left[\begin{array}{l}
V_{A} \\
V_{B} \\
V_{C}
\end{array}\right]=S\left[\begin{array}{c}
V_{A} \\
V_{B} \\
V_{C}
\end{array}\right]} \\
& {\left[\begin{array}{l}
I_{A} \\
I_{B} \\
I_{C}
\end{array}\right]=\left[\begin{array}{lll}
S_{A a} & S_{A b} & S_{A c} \\
S_{B a} & S_{B b} & S_{B c} \\
S_{C a} & S_{C b} & S_{C c}
\end{array}\right]\left[\begin{array}{l}
I_{a} \\
I_{b} \\
I_{c}
\end{array}\right]=S^{T}\left[\begin{array}{c}
I_{a} \\
I_{b} \\
I_{c}
\end{array}\right]}
\end{aligned}
$$

where $S$ and its transpose $S^{T}$ are transfer matrices obtained from controlling the matrix converter output voltages and input currents.

Each switch in the matrix can be assigned a value of zero for the off state and one for on state. Therefore there are in total $2^{9}=512$ possible switch combinations in the transfer matrix $R$; however only 27 switch states are allowable because switch states that short circuit the input sources or open circuit motor terminals must be avoided. In a similar manner to space vector modulation (SVM), each switch state corresponds to an input voltage and an output current space vector. These 27 states are composed of three groups: active (18), zero (3) and rotating (6) vectors. Rotating vectors cannot be usefully applied because their locations (angles) keep changing.

Active vectors are numbered $( \pm 1, \pm 2, \pm 3, \cdots, \pm 9)$ and summarized in Table I. These vectors have fixed locations and they form hexagons, as shown in Fig. 3, while their amplitudes vary with input voltages. In zero states, all the outputs of the matrix converter are connected to the same input resulting in vectors with zero amplitudes while angles are arbitrary. In SVM these active and zero vectors are applied to generate the desired output voltage and input current vectors at the same time. In DTC control, appropriate vectors are selected based on the prescribed switching look-up table according to the instantaneous stator flux and torque/speed information. This will be explained in Section IV. 


\section{INDUCTION MOTOR MODEL AND DTC THEORY}

In DTC controlled induction machine, the stator flux and torque are controlled directly by selecting the appropriate voltage vectors available in the drive converter. The stator flux is obtained from

$$
\psi_{s}=\int\left(V_{s}+R_{s} \cdot i_{s}\right) d t
$$

If the voltage drop across the stator resistor $R_{s}$ is neglected, then

$$
\psi_{s}=\int V_{s} d t
$$

where $\psi_{s}$ is the stator flux and $V_{s}$ is the voltage applied at the stator. Considering a short finite time $\Delta t$ (control cycle period), (4) can be approximately written as

$$
\Delta \psi_{s}=\Delta t \cdot V_{s}
$$

which means that the stator flux will change accordingly in the direction of the applied voltage vector. Therefore, the stator flux can be regulated by selecting suitable voltage vectors. In the stationary reference frame (synchronized with stator), the electromagnetic torque developed in an induction machine is

$$
T_{e}=\frac{3}{2} p \cdot \psi_{s} \cdot i_{s}
$$

which can be equivalently described as

$$
T_{e}=\frac{3}{2} p \cdot\left|\boldsymbol{\psi}_{s}\right| \cdot\left|\boldsymbol{i}_{s}\right| \cdot \sin \left(\theta_{i s}-\theta_{\psi s}\right)
$$

where $\boldsymbol{\psi}_{s}$ is the stator flux vector; $\boldsymbol{i}_{s}$ is the stator current

\begin{tabular}{|c|c|c|c|c|}
\hline No. & Switching states & Output voltage vectors & Input current vectors & Group \\
\hline+1 & स⿴囗十 & $V_{+1}=\frac{2}{\sqrt{3}} V_{i} \sin \left(\omega_{i} t+\frac{\pi}{6}\right) e^{j \cdot 0}$ & $I_{+1}=\frac{2}{\sqrt{3}} I_{o} \sin \left(\omega_{o} t-\varphi_{o}\right) e^{j--\frac{\pi}{6}}$ & \multirow{18}{*}{ active } \\
\hline+2 & 70 & $V_{+2}=\frac{2}{\sqrt{3}} V_{i} \sin \left(\omega_{i} t-\frac{\pi}{2}\right) e^{j \cdot 0}$ & $I_{+2}=\frac{2}{\sqrt{3}} I_{o} \sin \left(\omega_{o} t-\varphi_{o}\right) e^{j \cdot \frac{\pi}{2}}$ & \\
\hline+3 & 70 & $V_{+3}=\frac{2}{\sqrt{3}} V_{i} \sin \left(\omega_{i} t+\frac{5 \pi}{6}\right)$ & $I_{+3}=\frac{2}{\sqrt{3}} I_{o} \sin \left(\omega_{o} t-\varphi_{o}\right) e^{j \cdot \frac{7 \pi}{6}}$ & \\
\hline-1 & $\rightarrow$ & $V_{-1}=-\frac{2}{\sqrt{3}} V_{i} \sin \left(\omega_{i} t+\frac{\pi}{6}\right) e^{j \cdot 0}$ & $I_{-1}=-\frac{2}{\sqrt{3}} I_{o} \sin \left(\omega_{o} t-\varphi_{o}\right) e^{j-\frac{\pi}{6}}$ & \\
\hline-2 & 70 & $V_{-2}=-\frac{2}{\sqrt{3}} V_{i} \sin \left(\omega_{i} t-\frac{\pi}{2}\right) e^{j \cdot 0}$ & $I_{-2}=-\frac{2}{\sqrt{3}} I_{o} \sin \left(\omega_{o} t-\varphi_{o}\right) e^{j \cdot \frac{\pi}{2}}$ & \\
\hline-3 & 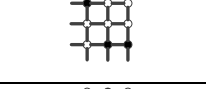 & $V_{-3}=-\frac{2}{\sqrt{3}} V_{i} \sin \left(\omega_{i} t+\frac{5 \pi}{6}\right) e^{j \cdot 0}$ & $I_{-3}=-\frac{2}{\sqrt{3}} I_{o} \sin \left(\omega_{o} t-\varphi_{o}\right) e^{j \cdot \frac{7 \pi}{6}}$ & \\
\hline+4 & \#保 & $V_{+4}=\frac{2}{\sqrt{3}} V_{i} \sin \left(\omega_{i} t+\frac{\pi}{6}\right) e^{j \cdot \frac{2 \pi}{3}}$ & $I_{+4}=\frac{2}{\sqrt{3}} I_{o} \sin \left(\omega_{o} t-\varphi_{o}-\frac{2 \pi}{3}\right) e^{j-\frac{\pi}{6}}$ & \\
\hline+5 & 70 & $V_{+5}=\frac{2}{\sqrt{3}} V_{i} \sin \left(\omega_{i} t-\frac{\pi}{2}\right) e^{j \cdot \frac{2 \pi}{3}}$ & $I_{+5}=\frac{2}{\sqrt{3}} I_{o} \sin \left(\omega_{o} t-\varphi_{o}-\frac{2 \pi}{3}\right) e^{j \cdot \frac{\pi}{2}}$ & \\
\hline+6 & $\overrightarrow{B O}_{0 \rightarrow 0}$ & $V_{+6}=\frac{2}{\sqrt{3}} V_{i} \sin \left(\omega_{i} t+\frac{5 \pi}{6}\right) e^{j \cdot \frac{2 \pi}{3}}$ & $I_{+6}=\frac{2}{\sqrt{3}} I_{o} \sin \left(\omega_{o} t-\varphi_{o}-\frac{2 \pi}{3}\right) e^{j \cdot \frac{7 \pi}{6}}$ & \\
\hline-4 & सH & $V_{-4}=-\frac{2}{\sqrt{3}} V_{i} \sin \left(\omega_{i} t+\frac{\pi}{6}\right) e^{j \cdot \frac{2 \pi}{3}}$ & $I_{-4}=-\frac{2}{\sqrt{3}} I_{o} \sin \left(\omega_{o} t-\varphi_{o}-\frac{2 \pi}{3}\right) e^{j-\frac{\pi}{6}}$ & \\
\hline-5 & 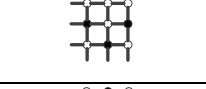 & $V_{-5}=-\frac{2}{\sqrt{3}} V_{i} \sin \left(\omega_{i} t-\frac{\pi}{2}\right) e^{j \cdot \frac{2 \pi}{3}}$ & $I_{-5}=-\frac{2}{\sqrt{3}} I_{o} \sin \left(\omega_{o} t-\varphi_{o}-\frac{2 \pi}{3}\right) e^{j \cdot \frac{\pi}{2}}$ & \\
\hline-6 & 30 & $V_{-6}=-\frac{2}{\sqrt{3}} V_{i} \sin \left(\omega_{i} t+\frac{5 \pi}{6}\right) e^{j \cdot \frac{2 \pi}{3}}$ & $I_{-6}=-\frac{2}{\sqrt{3}} I_{o} \sin \left(\omega_{o} t-\varphi_{o}+\frac{\pi}{3}\right) e^{j \cdot \frac{7 \pi}{6}}$ & \\
\hline+7 & 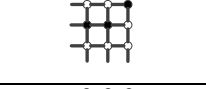 & $V_{+7}=\frac{2}{\sqrt{3}} V_{i} \sin \left(\omega_{i} t+\frac{\pi}{6}\right) e^{j \cdot \frac{4 \pi}{3}}$ & $I_{+7}=\frac{2}{\sqrt{3}} I_{o} \sin \left(\omega_{o} t-\varphi_{o}+\frac{2 \pi}{3}\right) e^{j-\frac{\pi}{6}}$ & \\
\hline+8 & 7 & $V_{+8}=\frac{2}{\sqrt{3}} V_{i} \sin \left(\omega_{i} t-\frac{\pi}{2}\right) e^{j \cdot \frac{4 \pi}{3}}$ & $I_{+8}=\frac{2}{\sqrt{3}} I_{o} \sin \left(\omega_{o} t-\varphi_{o}+\frac{2 \pi}{3}\right) e^{j \cdot \frac{\pi}{2}}$ & \\
\hline+9 & $\mathrm{BOH}$ & $V_{+9}=\frac{2}{\sqrt{3}} V_{i} \sin \left(\omega_{i} t+\frac{5 \pi}{6}\right) e^{j \cdot \frac{4 \pi}{3}}$ & $I_{+9}=\frac{2}{\sqrt{3}} I_{o} \sin \left(\omega_{o} t-\varphi_{o}+\frac{2 \pi}{3}\right) e^{j \cdot \frac{7 \pi}{6}}$ & \\
\hline-7 & 蔯 & $V_{-7}=-\frac{2}{\sqrt{3}} V_{i} \sin \left(\omega_{i} t+\frac{\pi}{6}\right) e^{j \cdot \frac{4 \pi}{3}}$ & $I_{-7}=-\frac{2}{\sqrt{3}} I_{o} \sin \left(\omega_{o} t-\varphi_{o}+\frac{2 \pi}{3}\right) e^{j-\frac{\pi}{6}}$ & \\
\hline-8 & $\hat{+10}$ & $V_{-8}=-\frac{2}{\sqrt{3}} V_{i} \sin \left(\omega_{i} t-\frac{\pi}{2}\right) e^{j \cdot \frac{4 \pi}{3}}$ & $I_{-8}=-\frac{2}{\sqrt{3}} I_{o} \sin \left(\omega_{o} t-\varphi_{o}+\frac{2 \pi}{3}\right) e^{j \cdot \frac{\pi}{2}}$ & \\
\hline-9 & 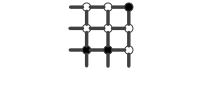 & $V_{-9}=-\frac{2}{\sqrt{3}} V_{i} \sin \left(\omega_{i} t+\frac{5 \pi}{6}\right) e^{j \cdot \frac{j \pi}{3}}$ & $I_{-9}=-\frac{2}{\sqrt{3}} I_{o} \sin \left(\omega_{o} t-\varphi_{o}+\frac{2 \pi}{3}\right) e^{j \cdot \frac{7 \pi}{6}}$ & \\
\hline
\end{tabular}
vector; $p$ is the pole pair number of the motor; and ' $|\boldsymbol{V}|$ ' implies the amplitude of the vector $\boldsymbol{V}$. $\theta_{i s}$ and $\theta_{\psi s}$ are the

TABLE I

ACTIVE STATES OF MATRIX CONVERTER SWITCH STATES 
stator current angle and stator flux angle respectively; both are referred to the stationary reference frame as shown in Fig. 4. In (7), $\left|\psi_{s}\right|$ is normally set to a constant value in DTC. Since the rotor time constant is usually larger than the stator time constant, the rotor flux can be assumed constant ( $d$-axis components of stator current) taking into consideration the fast control response. Therefore, the change of torque, at certain speeds, requires the change of stator flux angle $\theta_{\psi s}$ if the stator flux amplitude is maintained constant [4]. Therefore, if a voltage vector, which is able to maintain the stator flux amplitude while changing the stator flux to the desired position is selected, the torque can be regulated instantaneously.

DTC requires the estimation of stator flux and torque, which can be achieved using

$$
\begin{gathered}
\psi_{\beta s}=\int\left(V_{\beta s}-R_{s} \cdot i_{\beta s}\right) d t, \quad \psi_{\alpha s}=\int\left(V_{\alpha s}-R_{s} \cdot i_{\alpha s}\right) d t \\
\psi_{s}=\sqrt{\psi_{\alpha s}^{2}+\psi_{\beta s}^{2}} \quad \theta_{\psi s}=\tan ^{-1}\left(\psi_{\beta s} / \psi_{\alpha s}\right) \\
T_{e}=\frac{3}{2} p\left(\psi_{\alpha s} i_{\beta s}-\psi_{\beta s} i_{\alpha s}\right)
\end{gathered}
$$

These are developed in the stationary reference frame $(\alpha$ $\beta)$. As can be seen, the estimation only needs the rotor resistance, which is independent of other motor parameters.

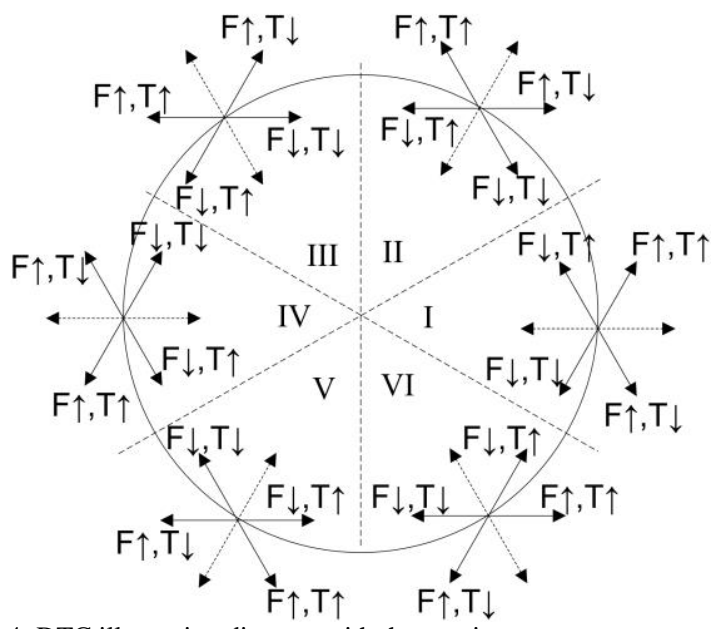

Fig. 4. DTC illustration diagram with the matrix converter vectors.

\section{DTC CONTROL FOR MATRIX CONVERTER DRIVES}

According to the above description, DTC can control the torque and flux directly via applying opposite voltage vectors available in drive converters. The voltage space vectors generated in a matrix converter were presented in Section II. The selection of the voltage vectors is based on the flux and torque error information.

\section{A. Common DTC Scheme}

The DTC controller diagram for the matrix converter is shown in Fig. 5. There are two operation modes: torque control mode and speed control mode. As shown in the figure, the hysteresis comparators output signals in the DTC to select the voltage vectors. In each flux sector (I to VI), different voltage vectors will have different effects on both the flux and torque, as illustrated in Fig. 4. In this figure, $(\mathrm{F} \uparrow, \mathrm{T} \downarrow)$ indicates the flux and torque will be increased and decreased respectively if that voltage vector is selected, e.g. the voltage vectors $( \pm 4, \pm 5, \pm 6)$ for sector I. Further selection of the voltage vectors depend on the input voltage vector locations. Some vectors are not used as they may have varying effects on torque and flux in the specific sector such as voltage vectors $( \pm 1, \pm 2$, \pm 3 ) in sector I.

A switching look-up table for the matrix converter based DTC can be adapted from the DTC scheme for VSI as their voltage vectors have the same layout (six directions with $60^{\circ}$ apart from each other). However, in the matrix converter, there are more active voltage vectors available corresponding to a specific voltage vector in VSI. These vectors have different amplitudes although they may all be able to achieve the goals of controlling the stator flux and toque.

In the most common matrix converter DTC, only two vectors with the maximum amplitude are considered to achieve a fast-dynamic response and simplicity. In fact, these two vectors have different effects on the input current, thus the input power factor. Therefore, the input power factor can be controlled by making use of this flexibility. However, this results in a heavier computation burden and higher switching frequency, thus higher switching losses.

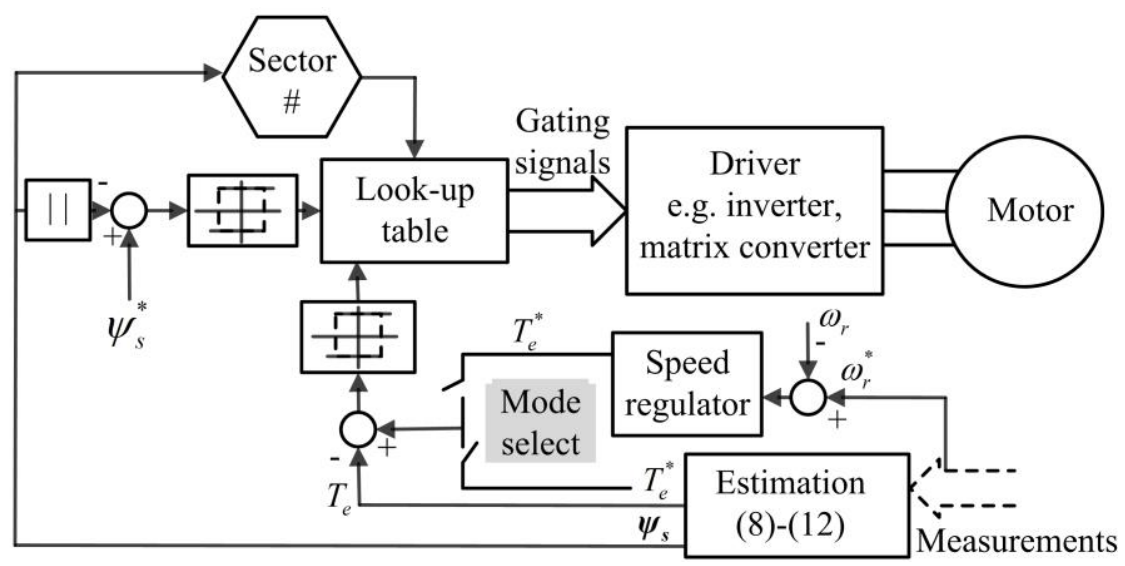

Fig. 5. Block diagram of DTC for motor drive with inverter or matrix converter. 
TABLE II

MODIFIED SWITCHING LOOK-UP TABLE FOR MATRIX CONVERTER DTC.

\begin{tabular}{|c|c|c|c|c|c|c|c|c|}
\hline \multirow{2}{*}{$\begin{array}{c}\text { New input voltage } \\
\text { sector \# }\end{array}$} & \multicolumn{8}{|c|}{ Selected voltage vector \# in VSI } \\
\hline & $V_{\mathrm{I} 1}$ & $V_{\mathrm{I} 2}$ & $V_{\mathrm{I} 3}$ & $V_{\mathrm{I} 4}$ & $V_{\mathrm{I} 5}$ & $V_{\mathrm{I} 6}$ & $V_{\mathrm{I} 7}$ & $V_{\mathrm{I} 8}$ \\
\hline I & $V_{-3}$ & $V_{+9}$ & $V_{-6}$ & $V_{+3}$ & $V_{-9}$ & $V_{+6}$ & $V_{01}, V_{03}$ & $V_{01}, V_{03}$ \\
\hline II & $V_{+2}$ & $V_{-8}$ & $V_{+5}$ & $V_{-2}$ & $V_{+8}$ & $V_{-5}$ & $V_{02}, V_{03}$ & $V_{02}, V_{03}$ \\
\hline III & $V_{-1}$ & $V_{+7}$ & $V_{-4}$ & $V_{+1}$ & $V_{-7}$ & $V_{+4}$ & $V_{01}, V_{02}$ & $V_{01}, V_{02}$ \\
\hline IV & $V_{+3}$ & $V_{-9}$ & $V_{+6}$ & $V_{-3}$ & $V_{+9}$ & $V_{-6}$ & $V_{01}, V_{03}$ & $V_{01}, V_{03}$ \\
\hline $\mathrm{V}$ & $V_{-2}$ & $V_{+8}$ & $V_{-5}$ & $V_{+2}$ & $V_{-8}$ & $V_{+5}$ & $V_{02}, V_{03}$ & $V_{02}, V_{03}$ \\
\hline VI & $V_{+1}$ & $V_{-7}$ & $V_{+4}$ & $V_{-1}$ & $V_{+7}$ & $V_{-4}$ & $V_{01}, V_{02}$ & $V_{01}, V_{02}$ \\
\hline
\end{tabular}

\section{B. DTC with a Modified Switching Table}

Since the amplitudes of the voltage vectors are related to the input voltage vector location (sector number), the input voltage vector sector may be sub-divided or redefined so that only one maximum output voltage vector is available in each sector. In the proposed scheme, the input voltage vector sectors are moved forward by $30^{\circ}$ compared with the conventional scheme as shown in Fig. 6 . In this way, the maximum voltage vectors available in each sector is only one instead of two. For example, in the newly defined input voltage vector sector $\mathrm{I}$, the output voltage vector -3 has the maximum amplitude. The selection of the maximum vector can assure the fastdynamic response and this further simplifies the switching table, thus the control implementation.

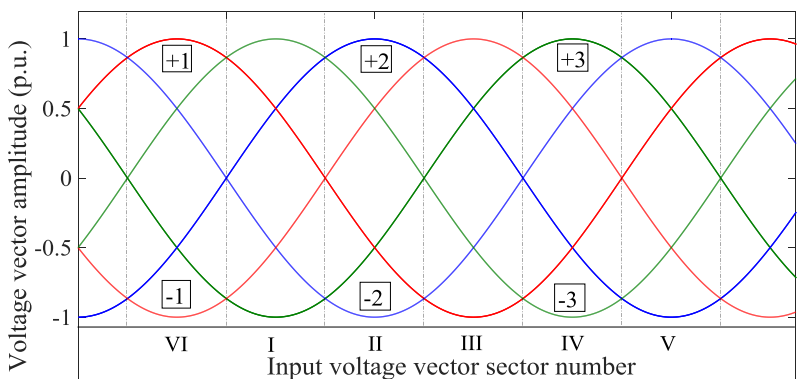

Fig. 6. Redefined input voltage vector sector for deciding the amplitudes of the output voltage vectors.

The modified switching look-up table, as shown in Table II, can be obtained in a straightforward manner from the VSI DTC look-up table. The appropriate selection of the zero vectors is beneficial to reduce the switch actions and switching frequency. There are two zero vectors available in the last two columns of Table II, however only one will be applied depending on the previous switch state.

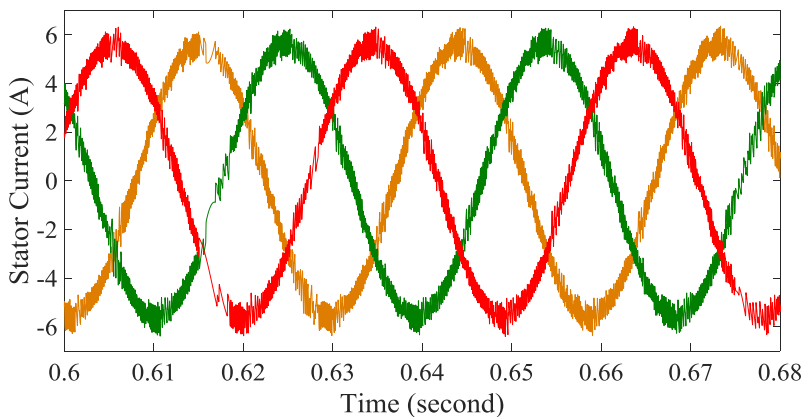

Fig. 7. Motor steady-state stator current when speed is $1000 \mathrm{rpm}$ and load torque is $10 \mathrm{~N} \cdot \mathrm{m}$.
TABLE. II

INDUCTION MACHINE SIMULATION PARAMETERS

\begin{tabular}{|c|c|c|c|c|c|c|}
\hline$R_{s}(\Omega)$ & $R_{r}(\Omega)$ & $L_{s}(\mathrm{H})$ & $L_{r}(\mathrm{H})$ & $L_{m}(\mathrm{H})$ & $p$ & $T_{s}(\mathrm{~s})$ \\
\hline 3.126 & 1.879 & 0.23 & 0.23 & 0.221 & 2 & $1 \times 10^{-5}$ \\
\hline
\end{tabular}

\section{Simulation Results}

The simulation results of the DTC matrix converter drive are presented in this section. The speed control mode is examined and the parameters used for the speed PI controller are $K_{p}=30$ and $K_{i}=0.05$. The hysteresis bands of the hysteresis comparators for the stator flux and torque are 0.5 and 0.01 respectively. Other simulation parameters are tabulated in Table III. The steady-state tests were performed first. Fig. 7 shows the motor steadystate stator current. The surge current is observed at the start of the motor. Fig. 8 presents the electromagnetic torque of the motor. The torque exhibits big ripples, which is a known weakness of DTC. Fig. 9 shows the stator flux locus. It can be seen that the flux can be controlled effectively (the reference is $0.9876 \mathrm{~Wb}$ ).

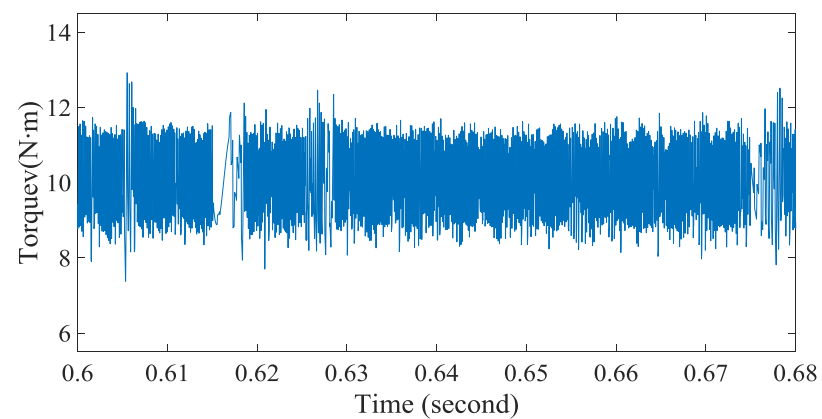

Fig. 8. Motor steady-state electromagnetic torque when speed is 1000 $\mathrm{rpm}$ and load torque is $10 \mathrm{~N} \cdot \mathrm{m}$.

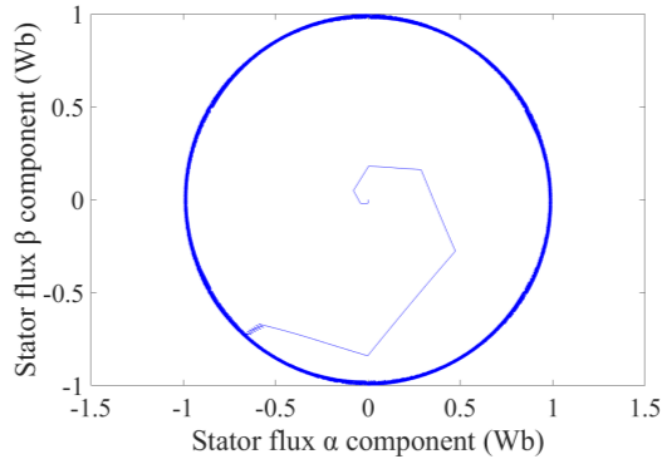

Fig. 9. Steady-state stator flux locus when speed is $1000 \mathrm{rpm}$ and load torque is $10 \mathrm{~N} \cdot \mathrm{m}$.

The transient performance of the proposed controller is evaluated under a step change of the load torque from 5 $\mathrm{N} \cdot \mathrm{m}$ to $-5 \mathrm{~N} \cdot \mathrm{m}$ at $0.65 \mathrm{~s}$ when the speed is $1000 \mathrm{rpm}$. Fig. 10 shows that the controller has a fast torque 
dynamic response. The transient stator currents are shown in Fig. 11. The performance of the DTC is independent of the motor parameters except for the stator resistance. Simulation results verify that the proposed DTC controller is effective in controlling the matrix converter based driver.

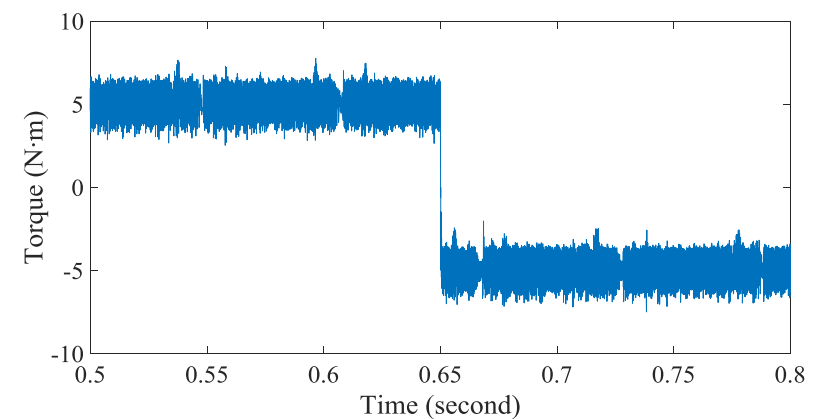

Fig. 10. Torque transient response to a step change at $0.65 \mathrm{~s}$.

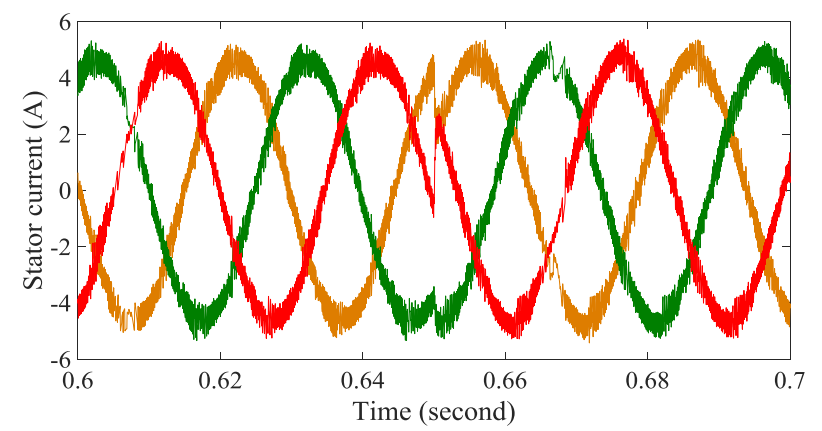

Fig. 11. Stator current for a toque step change at $0.65 \mathrm{~s}$.

\section{CONCLUSIONS}

DTC has developed very quickly in both research and industry because of direct torque and flux control, and fast torque dynamic response. DTC requires no coordinate transformations, current controller, or modulation stage. The implementation of DTC for a matrix converter drive is explained in this paper. The modified switching look-up table is obtained via redefining the input voltage vector sectors. As a result, only one maximum voltage space vector corresponding to each VSI voltage vector is available. In this way, a fastdynamic response is maintained, and switch actions and switching losses are reduced. Simulation results for an induction machine with the proposed controller are shown and they verify the controller effectiveness. Future work will be carried out to implement the multi-band hysteresis comparators and to deal with torque ripple.

\section{REFERENCES}

[1] I. Takahashi, and T. Noguchi, "A new quick-response and high-efficiency control strategy of an induction motor," IEEE Trans. Ind. Appl., vol. IA-22, no. 5, pp. 820-827, 1986.

[2] D. Casadei, G. Serra, A. Tani, "The use of matrix converters in direct torque control of induction machines," IEEE Trans. Ind. Electron., vol. 48, no. 6, pp. 1057-1064, 2001.

[3] S. Sebtahmadi, H. Pirasteh, S. H. Kaboli, A. Radan, and S. Mekhilef, "A 12-sector space vector switching scheme for performance improvement of matrix-converter-based DTC of IM drive," IEEE Trans. Power Electron., vol. 30, no. 7 , pp. 3804-3817, 2015.

[4] H. Abu-Rub, A. Iqbal, J. Guzinski, High performance control of AC drives with MATLAB/Simulink models. John Wiley \& Sons, 2012.

[5] C. Ortega, A. Arias, C. Caruana, J. Balcells, and G. M. Asher, "Improved waveform quality in the direct torque control of matrix-converter-fed PMSM drives," IEEE Trans. Ind. Electron., vol. 57, no. 6, pp. 2101-2110, 2010.

[6] D. Mohan, X. Zhang, and G. Foo, "Generalized DTC Strategy for Multilevel Inverter fed IPMSMs with Constant Inverter Switching Frequency and Reduced Torque Ripples," IEEE Trans. Energy Conversion, vol. pp, no. 99, pp. 1, 2017.

[7] Y. S. Choi, H. H. Choi, and J. W. Jung, "Feedback linearization direct torque control with reduced torque and flux ripples for IPMSM drives," IEEE Trans. Power Electron., vol. 31, no. 5, pp. 3728-3737, 2016.

[8] F. Khoucha, S. M. Lagoun, K. Marouani, A. Kheloui, and M. Benbouzid, "Hybrid cascaded H-bridge multilevelinverter induction-motor-drive direct torque control for automotive applications," IEEE Trans. Ind. Electron., vol. 57, no. 3, pp. 892-899, 2010.

[9] G. S. Buja, and M. P. Kazmierkowski, "Direct torque control of PWM inverter-fed AC motors-a survey," IEEE Trans. Ind. Electron., vol. 51, no. 4, pp. 744-757, 2004.

[10] C. Xia, J. Zhao, Y. Yan, T. Shi, "A novel direct torque control of matrix converter-fed PMSM drives using duty cycle control for torque ripple reduction," IEEE Trans. Ind. Electron., vol. 61, no. 6, pp. 2700-2713, 2014.

[11] K. B. Lee, and F. Blaabjerg, "Sensorless DTC-SVM for induction motor driven by a matrix converter using a parameter estimation strategy," IEEE Trans. Ind. Electron., vol. 55, no. 2, pp. 512-521, 2008.

[12] P. W. Wheeler, J. Rodriguez, J. C. Clare, L. Empringham and A. Weinstein, "Matrix converters: a technology review," IEEE Trans. Ind. Electron., vol. 49, no. 2, pp. 276-288, 2002.

[13] S. Sebtahmadi, H. Pirasteh, S. Hr Aghay Kaboli, A. Radan, and S. Mekhilef, "A 12-sector space vector switching scheme for performance improvement of matrix-converterbased DTC of IM drive," IEEE Trans. Power Electron., vol. 30, no. 7, pp. 3804-3817, 2015.

[14] S. F. Pinto, P. V. Mendes and J. Fernando Silva, "Modular matrix converter based solid state transformer for smart grids," Electric Power Syst. Research, vol. 136, pp. 189200, 2016.

[15] J. Zhang, L. Li, and D. G. Dorrell, "DQ Coupling Suppressed PID Controller for the Transmission Line Power Flow Control Using a Matrix Converter," IEEE Ind. Electron. Soc. Annu. Meeting (IECON16), Florence, Italy, pp. 6249 -6254, October 2016.

[16] J. Zhang, D. G. Dorrell, and L. Li, "Applications of the Direct Space Vector Modulation Controlled Matrix Converter as the Unified Power Flow Controller," 8th Int. conf. power electron. motor drives (PEDS), Glasgow, UK, pp. 6, April 2016.

[17] J. Zhang, L. Li, Z. Malekjamshidi, and D. G. Dorrell, "Predictive Voltage Control of Direct Matrix Converter with Reduced Number of Sensors for the Renewable Energy and Microgrid Applications," IEEE Energy Conversion Congress and Exposition (ECCE), Cincinnati, USA, Sept 2017

[18] Y. Bak, E. Lee, and K. B. Lee, "Indirect matrix converter for hybrid electric vehicle application with three-phase and single-phase outputs," Energies, vol. 8, no. 5, pp. 38493866, 2015. 